 \\ www4.fsanet.com.br/revista
}

Rev. FSA, Teresina, v. 18, n. 03, art. 13, p. 279-298, mar. 2021

ISSN Impresso: 1806-6356 ISSN Eletrônico: 2317-2983 http://dx.doi.org/10.12819/2021.18.03.13

\section{Estado do Conhecimento Sobre Juventudes e Consumo}

\section{State of Knowledge About Youth and Consumption}

Leonardo Brião de Oliveira

Graduando em Ciências Sociais na Universidade Federal do Rio Grande do Sul

E-mail: leocienciasocial@gmail.com

Victor Hugo Nedel Oliveira

Doutor em Educação pela Pontifícia Universidade Católica do Rio Grande do Sul Professor da Universidade Federal do Rio Grande do Sul

E-mail: victor.juventudes@gmail.com

Endereço: Leonardo Brião de Oliveira

UFRGS - Av. Bento Gonçalves, 9500, prédio 43815, gabinete 210, Agronomia, CEP: 91.509-900, Porto Alegre/RS, Brasil.

Endereço: Victor Hugo Nedel Oliveira

UFRGS - Av. Bento Gonçalves, 9500, prédio 43815, gabinete 210, Agronomia, CEP: 91.509-900, Porto Alegre/RS, Brasil.
Editor-Chefe: Dr. Tonny Kerley de Alencar Rodrigues

Artigo recebido em 10/02/2021. Última versão recebida em 22/02/2021. Aprovado em 23/02/2021.

Avaliado pelo sistema Triple Review: a) Desk Review pelo Editor-Chefe; e b) Double Blind Review (avaliação cega por dois avaliadores da área).

Revisão: Gramatical, Normativa e de Formatação 


\title{
RESUMO
}

O presente trabalho compreende a construção do Estado de Conhecimento acerca do tema 'juventudes e consumo', realizada a partir de trabalhos selecionados na Biblioteca Digital Brasileira de Teses e Dissertações (BDTD). A metodologia consistiu no levantamento bibliográfico, realizado sobre a base de dados da BDTD, configurado sob o recorte temporal entre os anos de 2015-2019 e utilizando-se, para as buscas, das palavras-chave: jovens, juventudes, consumo e consumismo. Para selecionar os trabalhos que surgiram da busca, realizou-se uma leitura flutuante, resultando em oito trabalhos. Destaca-se nos resultados uma maioria de dissertações em relação às teses, a majoritariedade das Ciências Sociais nos trabalhos, a predominância das instituições públicas pelas quais as pesquisas partiram, bem como para o financiamento delas, e os temas identidade e mídia, que foram os mais abordados pelas pesquisas. Dessa forma, pode-se concluir que as instituições públicas têm um papel importante para as pesquisas no campo das juventudes; que as Ciências Sociais possuem um interesse maior sobre o tema quando comparado a outras áreas, e que isso se reflete nos referenciais teóricos e métodos utilizados; e que os temas relacionados à juventude e consumo estão voltados, principalmente, para as questões relacionadas à identidade e as mídias.

Palavras-chave: Juventudes. Jovens. Consumo. Consumismo. Estado de Conhecimento.

\begin{abstract}
The present work comprises the construction of the State of Knowledge on the theme 'youths and consumption', carried out from works selected at the Brazilian Digital Library of Theses and Dissertations (BDTD). The methodology consisted of a bibliographic survey, carried out on the BDTD database, configured under the time frame between the years 2015-2019 and using, for the searches, the keywords: young people, youth, consumption and consumerism. To select the jobs that emerged from the search, a fluctuating reading was performed, resulting in eight jobs. The results stand out in the majority of dissertations in relation to the theses, the majority of Social Sciences in the works, the predominance of public institutions through which the researches started, as well as for their funding, and the themes identity and media, which were most covered by research. Thus, it can be concluded that public institutions have an important role for research in the field of youth; that the Social Sciences have a greater interest on the subject when compared to other areas, and that this is reflected in the theoretical references and methods used; and that themes related to youth and consumption are mainly focused on issues related to identity and the media.
\end{abstract}

Keywords: Youths. Young. Consumption. Consumerism. State of Knowledge. 


\section{INTRODUÇÃO}

A juventude é uma categoria social há muito tempo dada, pelas mídias tradicionais e pelo senso comum, como homogênea, passiva e transgressora, ainda que em termos estéticos e de consumo, é tida como um modelo a se perseguir. Esta visão estigmatizadora e, ao mesmo tempo, contraditória - na medida em que outros pontos são exaltados - é superficial diante de todas as problemáticas históricas e sociais que remetem a questões geracionais, de classe social, de contexto econômico e político, etc (OLIVEIRA et al, 2018; OLIVEIRA, 2021). Apesar de muitos problemas, fenômenos e experiências serem compartilhados por muitos jovens, tais constatações não podem se tornar uma barreira para entender a diversidade dessa categoria social, ainda mais quando essa homogeneização a apassivação institucional e ideológica é imposta e forçada sobre os jovens, de maneira a condiciona-los dentro de uma estrutura social. Sobre isso, já dizia Pais (1990, p. 151): “[...] a juventude deve ser olhada não apenas na sua aparente unidade, mas também na sua diversidade.”. A partir daí, torna-se necessário um olhar sobre as juventudes que as qualifiquem sob diversos aspectos da realidade que as atingem, ou seja, os aspectos econômicos, cultural, social, político, contextual, entre uma infinidade de outros aspectos.

O fato é que a juventude deve ser encarada, antes de tudo, como uma complexa construção social, e como tal, sua concepção variou muito durante os diferentes períodos das sociedades, sendo que em tempos passados ela nem existira (PAIS et al, 2017). Dayrell (2003, p. 41) já assinalava parte dessa ideia: "Construir uma definição de juventude não é fácil, principalmente porque os critérios que a constituem são históricos e culturais. "Sendo assim, não há como pensá-la como uma categoria estática e natural das sociedades, mas como produto destas.

As discussões mais avançadas dessa definição de juventude estabelecem o plural da palavra (SANTOS et al, 2019), ou seja, a juventude passou a ser vista a partir de sua pluralidade, provocando, assim, o reconhecimento de que não existe apenas uma juventude, mas várias juventudes em um mesmo espaço de tempo e ao longo da história.

Já o debate sobre consumo, tem se mostrado potente nas ciências humanas, principalmente quando o capitalismo começou a incorporar fortemente a propaganda como tática de fomentar esta prática, intensificando o fenômeno pelo qual se chama de consumismo - ou cultura do consumo (FONTANELLE, 2017). O consumo, como a antropologia tem historicamente demonstrado, é algo comum a todas as sociedades humanas, enquanto entendido como o uso das coisas (seja para necessidades biológicas ou culturais), mas toma 
uma forma diferente quando se o realiza no capitalismo, onde tudo é passível de virar mercadoria. Em muitas sociedades o consumo aparece sobre diversas práticas, às vezes sendo fundamental para a manutenção social, mas o capitalismo irá elevar o consumo a níveis extremos. No século XIX, Marx (1867) já dizia que "A riqueza das sociedades em que domina o modo-de-produção capitalista apresenta-se como uma "imensa acumulação de mercadorias". O resultado desse modo de produção e estimulo ao consumo do sistema capitalista é a cultura do consumo, mais conhecida como consumismo. O consumismo, então, é um fenômeno mais profundo na vida dos indivíduos, pois este se torna central nas relações sociais em razão de seu significado simbólico. É através do consumo que se formam as identidades, que se adentra em grupos, que se definem posições sociais, que se possibilita o acesso a determinados espaços e que, em última análise, permite que se possa exercer o papel de cidadão.

As sociedades contemporâneas estão mergulhadas em um século em que o consumo é uma prática central na vida dos indivíduos, de tal maneira que há uma relação de sobreposição do papel do consumo sobre a cidadania, na medida em que a segunda subjaz da primeira.

A lógica do consumo nos moldes da sociedade capitalista segue as leis de seus mercados, sendo estes, por razões orgânicas, expansionistas. Os jovens, dentro de sua dependência sistêmica baseada no consumo, são usados como ferramenta dessa expansão, a ponto de eles mesmos se tornaem mercadoria (BACKES, 2016). Na forma de mercadoria, o jovem é bem visto, na medida em que ele é o padrão ideal de imagem e de selecionadas características. Fora desse mundo, os jovens são normalmente tratados sob uma ótica reducionista, negativa, apassivadora, que o estigmatiza e o homogeneíza.

A etapa em que se produz o estado de conhecimento, por sua vez, proposta por este trabalho, busca estruturar em um determinado espaço de tempo uma conexão de diálogo dos autores da área de estudo (juventudes e consumo) com suas ideias de pesquisa, ao mesmo tempo em que estabelece uma relação de reflexividade entre autor e leitor-pesquisador, na medida em que surgem mais questionamentos, lacunas, variáveis, etc., a se compreender. Então, as análises produzidas por esta pesquisa, visam produzir uma síntese de uma amostra das discussões mais recentes sobre o tema, a fim de promover esclarecimentos e questionamentos.

O tema de pesquisa proposto por este trabalho (juventudes e consumo) nos expõe a uma determinada conjuntura histórico-social, com diferentes posições e forças, que se compreendem em um espaço. Os interesses dos diferentes atores da trama social, desse modo, muitas vezes se encontram nas entrelinhas e refletem também nas produções do campo 
acadêmico. Então, cabe ressaltar que a construção do estado de conhecimento busca também analisar e refletir sobre conjuntura sistêmica da qual as partes que a atravessam devem ser de interesse dos pesquisadores; Morosini e Fernandes (2014, p.156) assinalam isso quando falam: “[...] faz-se necessário considerar que a construção de uma produção cientifica está relacionada não só à pessoa/pesquisador que a produz, mas a influências da instituição na qual está inserida, do país em que vive e de suas relações com a perspectiva global.

O estado de conhecimento, então, tem papel fundamental para o pesquisador e para a pesquisa, principalmente na fase exploratória de um trabalho acadêmico, na medida em que produz um panorama do assunto a ser pesquisado, e é definido por Morosini e Fernandes (2014, p.155) nos seguintes termos: "Identificação, registro, categorização que levem à reflexão e à síntese sobre a produção científica de uma determinada área, em um determinado espaço de tempo, congregando periódicos, teses, dissertações e livros sobre uma temática específica".

Tendo em vista que o estado de conhecimento visa também essa promoção de novos conhecimentos, a partir dos apontamentos que se farão neste estudo acerca do tema juventudes e consumo, tentará se lançar novas problemáticas e lacunas a se explorar, promovendo, assim, o desenvolvimento científico, ainda mais no tema juventudes e consumo, um tema, sem dúvidas, muito complexo.

\section{METODOLOGIA}

Para a realização deste trabalho utilizou-se do levantamento bibliográfico (GIL, 2002), que consiste na busca de livros, revistas, artigos, teses e dissertações, os quais são delimitados sob uma série de fatores, tais como recorte temporal, idioma, tipo de trabalho, palavras-chave, etc., a fim de se atingir com a melhor qualidade o objeto que se pesquisa.

Escolheu-se a Biblioteca Digital Brasileira de Teses e Dissertações (BDTD), organizada pelo Instituto Brasileiro de Informação em Ciência e Tecnologia (IBICT), que é uma instituição governamental que, segundo o seu site, tem a missão de "promover a competência, o desenvolvimento de recursos e a infraestrutura de informação em ciência e tecnologia para a produção, socialização e integração do conhecimento científico e tecnológico".

A busca na BDTD foi do tipo avançada, e consistiu em pesquisar com as palavraschave: jovens, juventudes, consumo e consumismo, nos campos de busca, variando as suas ordens, de maneira a maximizar o alcance aos trabalhos dos temas de interesse. Outro filtro 
aplicado refere-se ao recorte temporal da pesquisa, que foi delimitado entre os anos de 2015 a 2019.

Para selecionar os trabalhos, realizou-se uma leitura flutuante em todos aqueles trabalhos em que os resumos apresentavam conteúdo relacionado com o tema em questão. Ao final, de 81 resultados, somente oito trabalhos foram selecionados por se alinharem ao tema da pesquisa. O processo de análise nos trabalhos selecionados dividiu-se em três partes principais, que abrigavam gráficos, textos e quadros, a fim de se organizar melhor os dados obtidos.

A primeira parte trata-se de um quadro que contém todos os trabalhos selecionados e informa o nome do (a) autor (a), o título do trabalho, o ano que foi publicado, o nível acadêmico e a universidade. A segunda parte abrange os dados quantitativos, que exploram os tipos de trabalho (dissertação ou tese), as instituições de ensino e financiamento envolvidas, o ano de publicação dos trabalhos, o conceito CAPES dos PPGs de origem dos trabalhos e a região de origem (Norte, Sul, Sudeste, etc) deles também. Já a terceira parte explora qualitativamente os resultados, de maneira a extrair os métodos e técnicas utilizados pelos trabalhos, seus objetivos principais, os temas mais latentes, as palavras-chave que mais se destacam etc.

Cabe ressaltar que, apesar das três secções de resultados, pode-se separá-los também em duas partes: o quadro de trabalhos selecionados e a análise quantitativa (primeira parte) traçariam um panorama dos campos científicos, considerando, assim, os aspectos externos ao conteúdo em si dos trabalhos selecionados; enquanto que a análise qualitativa (segunda parte) reflete justamente sobre aquilo que não foi aprofundado na primeira: o conteúdo produzido pelas pesquisas.

\section{RESULTADOS E DISCUSSÕES}

No quadro que segue podemos observar os trabalhos selecionados na Biblioteca Digital de Teses e Dissertações (BDTD), informando sobre o (a) autor (a), título, ano, nível (mestrado ou doutorado) e universidade. Cabe reforçar que foram selecionados somente trabalhos publicados entre 2015 a 2019. 
Quadro 1 - trabalhos selecionados

\begin{tabular}{|c|c|c|c|c|}
\hline Nome & Título & Ano & Nível & Universidade \\
\hline $\begin{array}{l}\text { BARREIRO, } \\
\text { Rafael Garcia }\end{array}$ & $\begin{array}{l}\text { Entre Redes: Juventudes, Ambientes } \\
\text { Virtuais e Vidas Entretidas }\end{array}$ & 2019 & $\begin{array}{l}\text { Doutorado em } \\
\text { Terapia } \\
\text { Ocupacional }\end{array}$ & $\begin{array}{l}\text { Universidade } \\
\text { Federal de São } \\
\text { Carlos }\end{array}$ \\
\hline $\begin{array}{l}\text { BRANDÃO, } \\
\text { Deyse de } \\
\text { Fátima do } \\
\text { Amarante }\end{array}$ & $\begin{array}{l}\text { Consumo como experiência social: } \\
\text { experimentações, vivências e práticas } \\
\text { da cultura pop em um coletivo juvenil }\end{array}$ & 2015 & $\begin{array}{l}\text { Mestrado em } \\
\text { Antropologia }\end{array}$ & $\begin{array}{l}\text { Universidade } \\
\text { Federal da } \\
\text { Paraíba }\end{array}$ \\
\hline $\begin{array}{l}\text { BRASIL, } \\
\text { Wener da } \\
\text { Silva }\end{array}$ & $\begin{array}{l}\text { O coletivo fora do eixo: juventude } \\
\text { organizada, produção, circulação e } \\
\text { consumo cultural }\end{array}$ & 2015 & $\begin{array}{l}\text { Mestrado em } \\
\text { Sociologia }\end{array}$ & $\begin{array}{r}\text { Univers } \\
\text { Federa } \\
\text { Sergi }\end{array}$ \\
\hline $\begin{array}{l}\text { COSTA, } \\
\text { Gisele Maria } \\
\text { Marino }\end{array}$ & $\begin{array}{l}\text { As músicas veiculadas pelas mídias } \\
\text { entre jovens: consumo, tendências e } \\
\text { comportamentos }\end{array}$ & 2015 & $\begin{array}{l}\text { Doutorado em } \\
\text { Educação }\end{array}$ & $\begin{array}{l}\text { Univers } \\
\text { Feder: } \\
\text { Minas } \\
\end{array}$ \\
\hline $\begin{array}{l}\text { MORAES, } \\
\text { Maria } \\
\text { Cristina } \\
\text { Bravo de }\end{array}$ & $\begin{array}{l}\text { As It-girls e o "quê" a mais de luxo: } \\
\text { cultura, juventude e mediação }\end{array}$ & 2017 & $\begin{array}{l}\text { Mestrado em } \\
\text { Comunicação } \\
\text { Social }\end{array}$ & $\begin{array}{c}\text { Pontifícia } \\
\text { Universidade } \\
\text { Católica do Rio } \\
\text { de Janeiro }\end{array}$ \\
\hline $\begin{array}{l}\text { PETENUSSI, } \\
\text { Felipe } \\
\text { Roberto }\end{array}$ & $\begin{array}{l}\text { O mosaico das identificações juvenis } \\
\text { via consumo: um estudo de } \\
\text { antropologia urbana em um shopping } \\
\text { de Ribeirão Preto/SP }\end{array}$ & 2017 & $\begin{array}{c}\text { Mestrado em } \\
\text { Ciências Sociais }\end{array}$ & $\begin{array}{l}\text { Universidade } \\
\text { Estadual } \\
\text { Paulista "Júlio } \\
\text { de Mesquita } \\
\text { Filho" } \\
\end{array}$ \\
\hline $\begin{array}{c}\text { SOUZA, } \\
\text { Izabela Janete } \\
\text { de }\end{array}$ & $\begin{array}{l}\text { Andarilhos Contemporâneos em } \\
\text { Belém, a Metrópole da Amazônia: } \\
\text { Consumo, Juventudes e Sociabilidade } \\
\text { na era dos Shoppings Centers }\end{array}$ & 2017 & $\begin{array}{l}\text { Doutorado em } \\
\text { Ciências Sociais }\end{array}$ & $\begin{array}{c}\text { Pontifícia } \\
\text { Universidade } \\
\text { Católica do Rio } \\
\text { de Janeiro }\end{array}$ \\
\hline $\begin{array}{l}\text { TOMAZ, } \\
\text { Cícero José }\end{array}$ & $\begin{array}{l}\text { Sociedade de consumo e juventude: } \\
\text { uma análise as partir das práticas de } \\
\text { consumo e identidade dos jovens } \\
\text { vinculados ao Fundo de Financiamento } \\
\text { Estudantil }\end{array}$ & 2016 & $\begin{array}{c}\text { Mestrado em } \\
\text { Consumo, } \\
\text { Cotidiano e } \\
\text { Desenvolvimento } \\
\text { Social } \\
\end{array}$ & $\begin{array}{l}\text { Universidade } \\
\text { Federal Rural } \\
\text { de Pernambuco }\end{array}$ \\
\hline
\end{tabular}

Fonte: Elaborado pelos autores (2021)

Pode-se observar neste quadro que há uma igualdade de gênero na medida em que há uma distribuição de 4 trabalhos para o gênero feminino e o masculino, o que mostra, nesse caso, que não há, aparentemente, um problema de gênero vinculada ao interesse de pesquisa com o tema juventudes e consumo; enquanto que, se tratando de referencial bibliográfico dos trabalhos selecionados, veremos uma maioria de autores do gênero masculino, o que reflete, por sua vez, uma desigualdade histórica em determinados campos científicos. Observa-se também que as áreas das ciências sociais são majoritárias; no entanto, tendo em vista as outras áreas que surgiram, percebe-se o interesse multidisciplinar ao tema.

Os gráficos a seguir buscam explorar, para além do conteúdo em si, das obras selecionadas, um panorama da produção acadêmica sob as delimitações de interesse desta pesquisa. 
Este gráfico refere-se aos tipos de trabalhos selecionados, que basicamente se delimitam em dois tipos: tese ou dissertação.

\section{Gráfico 1 - tipo de trabalho}

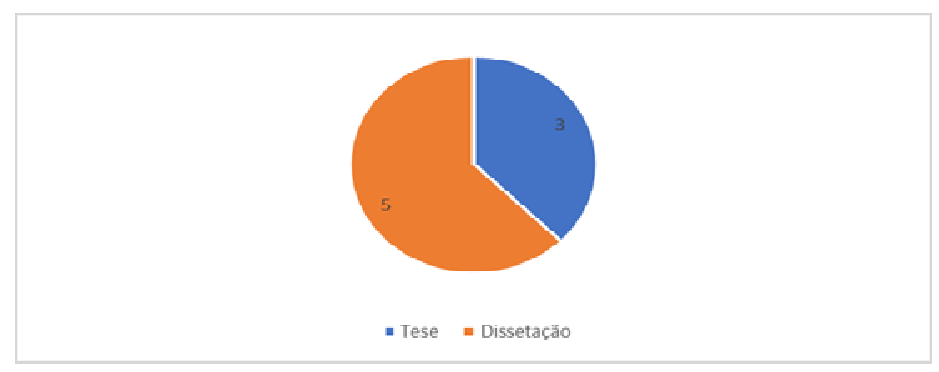

Fonte: Elaborado pelos autores (2021)

Nesse gráfico é possível observar que as dissertações, que estão relacionadas ao mestrado, somaram 5 trabalhos; enquanto que as teses, que remetem ao doutorado, somaram 3 trabalhos. Sendo assim, há mais mestres sobre o respectivo tema desta pesquisa do que doutores.

O gráfico seguinte informa o ano de publicação de cada obra selecionada, lembrando que a pesquisa foi realizada na BDTD, onde, através de uma busca avançada, realizou-se um recorte temporal de 5 anos: 2015 a 2019.

\section{Gráfico 2 - ano de publicação}

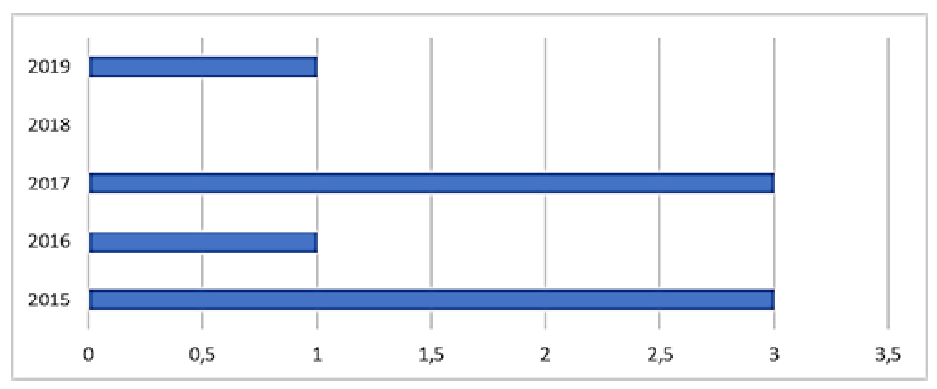

Fonte: Elaborado pelos autores (2021)

Podemos observar nestes resultados que a maioria dos trabalhos foi publicada nos anos de 2015 e 2017; enquanto que em 2016 e 2019 temos somente uma tese em cada ano. Em um cenário de vácuo de produção acadêmica tem-se o ano de 2018, que, dado que o financiamento de pesquisas vem cada vez mais diminuindo no Brasil, possivelmente corrobora com o cenário de tendência de queda nas pesquisas em geral, portanto, sendo uma vítima dessa queda de produção e financiamento científico. 
Neste gráfico reuniram-se as instituições onde foi produzido cada trabalho selecionado, a fim de produzir um panorama acerca das instituições acadêmicas de origem dos trabalhos.

Gráfico 3 - instituição de publicação

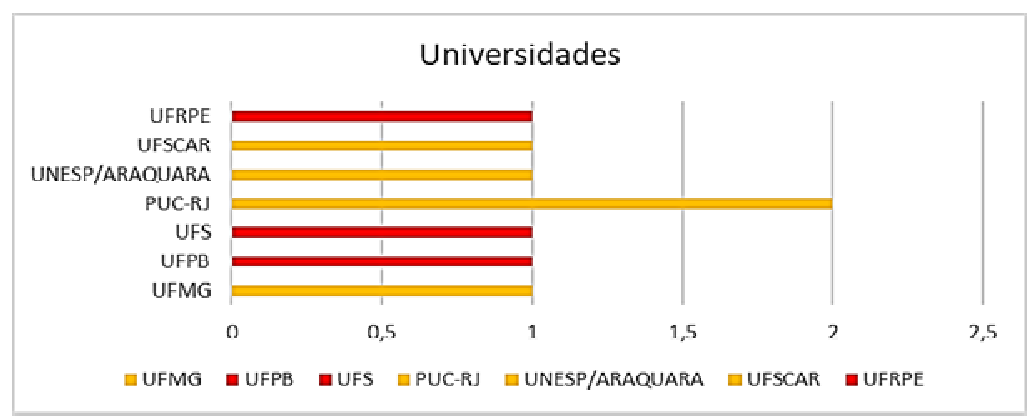

Fonte: Elaborado pelos autores (2021)

Pode-se observar nesse gráfico que duas regiões do país se destacam: sudeste (amarelo) e nordeste (vermelho); enquanto que outras não tiveram trabalhos para se selecionar. A universidade que mais teve produção foi a PUC-RJ, que se encontra na região sudeste. Com isso, pode-se verificar que, independente da região, a maior parte das universidades são públicas, valendo destaque apenas à PUC-RJ, no Sudeste, que é privada e que teve o maior número de produções.

O gráfico a seguir obteve, através da última avaliação quadrienal da CAPES realizada em 2017, os conceitos de cada PPG de origem dos trabalhos selecionados.

\section{Gráfico 4 - conceito CAPES}

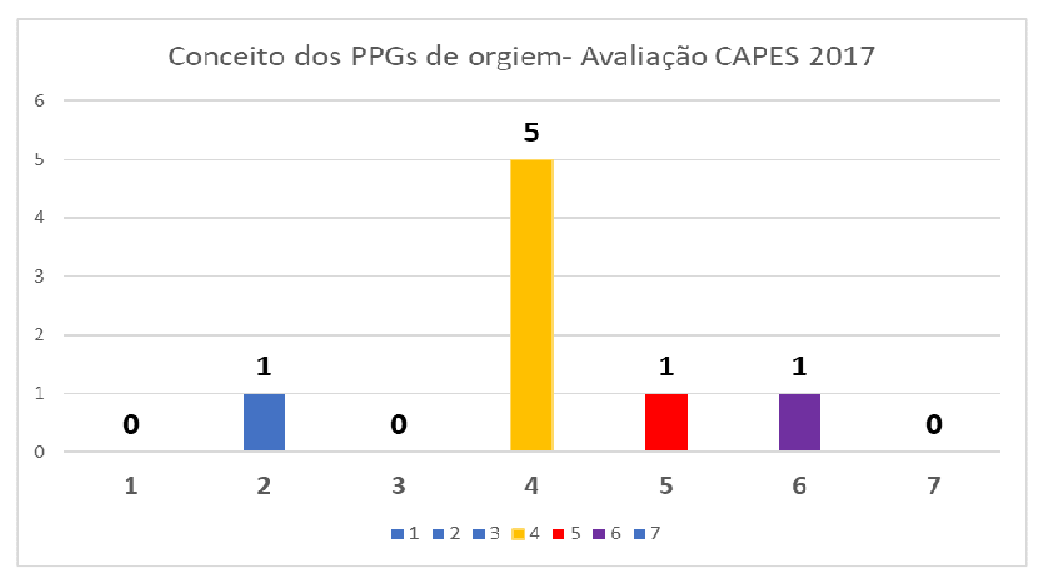

Fonte: Elaborado pelos autores (2021) 
Pode-se observar, então, que notoriamente temos a maioria dos PPGs com nota quatro. Tendo em vista a seguinte classificação de conceitos: de 1 a 2, desempenho ruim (não aprovado pela CAPES); de 3 a 5, desempenho satisfatório; de 6 a 7, desempenho excelente, consegue-se aferir que a maioria dos PPGs tem um desempenho entre o satisfatório e o excelente, enquanto que só um tem desempenho ruim na avaliação da CAPES.

Esse gráfico mostra a frequência dos trabalhos de acordo com as regiões de origem, pelas quais foram identificadas através das localizações das instituições acadêmicas.

\section{Gráfico 5 - região do país}

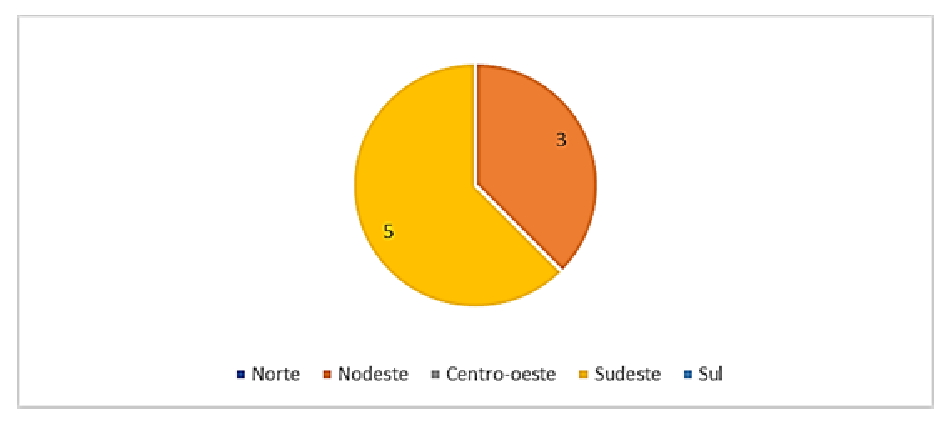

Fonte: Elaborado pelos autores (2021)

Os resultados deste gráfico mostram que a maioria dos trabalhos se concentra na região Sudeste, totalizando 5. Já o restante, 3, na região Nordeste. Nas outras regiões não houve trabalhos selecionados dentro das delimitações temporais e temáticas da pesquisa. Portanto, a região Sudeste demonstra maior interesse no tema juventudes e consumo quando comparado numericamente ao Nordeste.

O presente gráfico explora nos trabalhos o financiamento ou a ausência deste, sendo este suporte normalmente possibilitado através de bolsa de pesquisa.

\section{Gráfico 6 - financiamento}

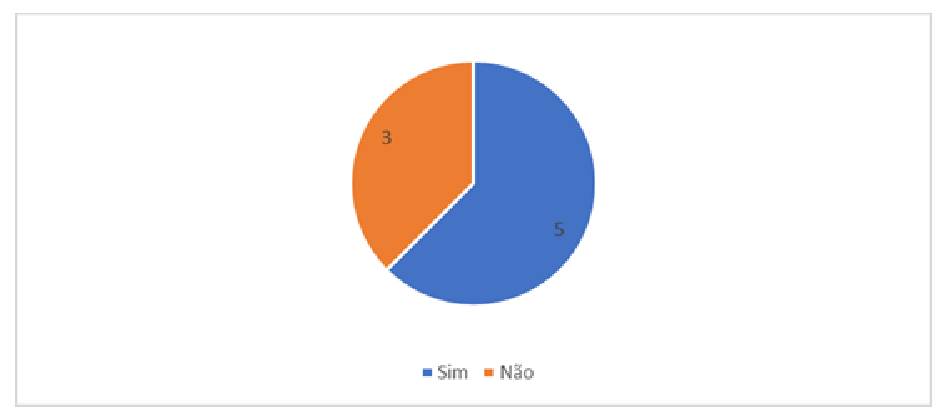

Fonte: Elaborado pelos autores (2021) 
Observamos nesse gráfico que 5 trabalhos (duas teses e três dissertações) foram financiados por bolsas de pesquisa, enquanto que os outros três trabalhos (dissertações), não. Sendo assim, vemos que a maioria dos trabalhos foi financiada por bolsas de pesquisa.

Neste último gráfico, exploram-se as agências financiadoras das bolsas de pesquisa, captadas nos trabalhos selecionados. Nota-se que o total de 5 trabalhos financiados já exclui aqueles outros três do gráfico anterior que não apresentaram financiamento.

\section{Gráfico 7 - agência da bolsa}

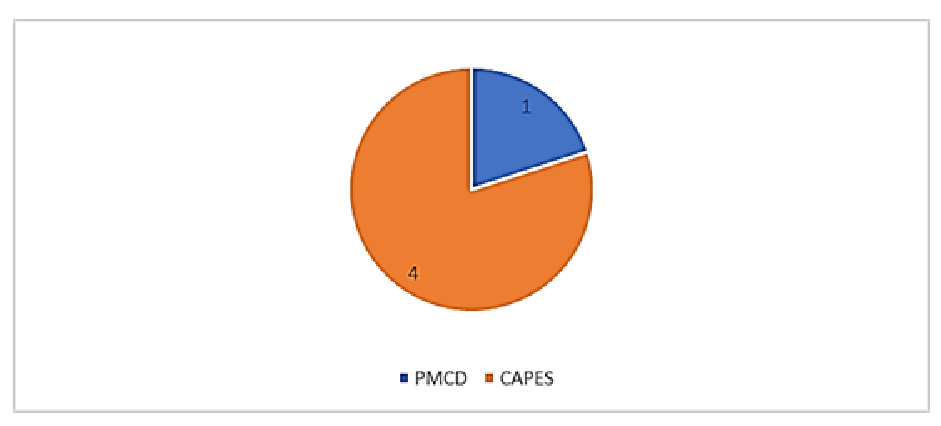

Fonte: Elaborado pelos autores (2021)

Observa-se que, dos cinco trabalhos vinculados às bolsas, todas foram CAPES (Coordenação de Aperfeiçoamento de Pessoal de Nível Superior), com exceção de uma tese, em 2015, que era PMCD (Programa Mineiro de Capacitação Docente). Ambas, CAPES e PMCD, recebem financiamento governamental, portanto, público, reforçando, assim, o que temos visto em alguns dos gráficos anteriores: a importância das instituições públicas para a pesquisa científica.

A análise qualitativa consistiu em selecionar um conjunto de dados através de distintas técnicas e métodos, onde os dados captados advêm da produção textual dos trabalhos selecionados, com exceção do gráfico que objetiva os métodos de pesquisa utilizados nas obras selecionadas. Seguem abaixo os dados obtidos.

Como primeira parte da análise qualitativa, reuniram-se todas as palavras-chave de cada trabalho selecionado e formulou-se uma nuvem de palavras pelas quais, de acordo com a variação de seu tamanho, expressam a frequência em que aparecem nos trabalhos. Quanto maior o tamanho das palavras, mais vezes elas aparecerem; quanto menor o tamanho delas, menos frequência elas tiveram. Para tanto, fez-se uso da ferramenta disponibilizada no site: wordart.com. O resultado da reunião das palavras-chave está na imagem de palavras abaixo. 
Figura 1 - palavras-chave dos trabalhos

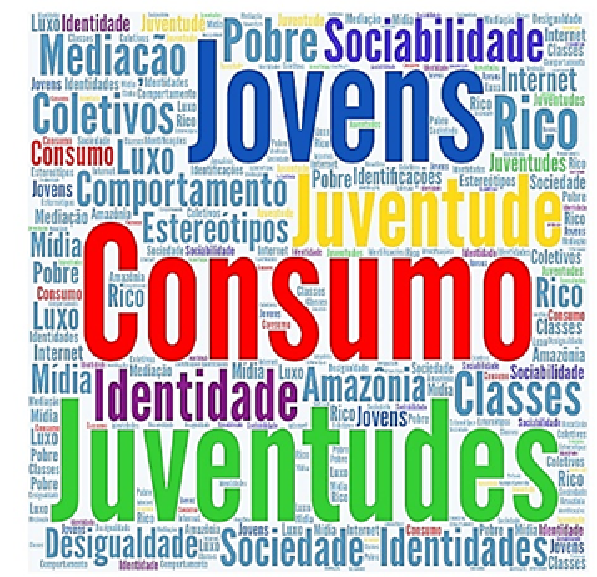

Fonte: Elaborado pelos autores (2021)

Como podemos observar nesta técnica de representação visual, jovens, juventudes e consumo são as palavras que mais se destacam, seguidas de identidade, juventude, pobre, rico, coletivos, etc. O destaque das palavras jovens, juventudes e consumo, em função de seu tamanho, mostra de certa forma que os trabalhos selecionados estão alinhados com o tema de estudo propostos por esta pesquisa, ao mesmo tempo em que agrega com outras palavras que abrem caminhos para a investigação de determinados outros aspectos sobre os dois temas principais, tais como identidade, sociabilidade, mediação e coletivos.

O quadro de objetivos propõe-se em reunir todos os objetivos principais das pesquisas selecionadas para fins de análise, dado que os objetivos refletem tendências políticas e ideológicas do pesquisador (Soriano, 2004).

\section{Quadro 2 - objetivos}

\begin{tabular}{|l|l|}
\hline \multicolumn{1}{|c|}{ Autor, data } & \multicolumn{1}{c|}{ Objetivo Geral da Investigação } \\
\hline BARREIRO, & $\begin{array}{l}\text { Analisar e discutir o uso das "redes sociais digitais" como ferramenta para } \\
\text { expressão dos modos de vida juvenis, das juventudes, buscando entender, através } \\
\text { dos influenciadores digitais, aspectos da sociabilidade nestes espaços, focalizando } \\
\text { seus resultados no que tange aos jovens de grupos populares urbanos. }\end{array}$ \\
\hline $\begin{array}{l}\text { BRANDRÃO, } \\
2015\end{array}$ & $\begin{array}{l}\text { Analisar, a partir do consumo, as relações juvenis dentro da cultura pop no Studio } \\
\text { Made in PB. }\end{array}$ \\
\hline BRASIL, 2015 & $\begin{array}{l}\text { Analisar a forma de organização contemporânea desse coletivo (Fora do Eixo), no } \\
\text { que diz respeito à produção, circulação e consumo cultural. }\end{array}$ \\
\hline COSTA, 2015 & $\begin{array}{l}\text { Investigar o papel das canções das mídias no cotidiano de alunos que frequentam } \\
\text { escolas de ensino básico. }\end{array}$ \\
\hline MORAES, 2017 & $\begin{array}{l}\text { Compreender o consumo sob a perspectiva cultural, considerando possíveis } \\
\text { contextos sociais. }\end{array}$ \\
\hline $\begin{array}{l}\text { PETENUSSI, } \\
2017\end{array}$ & $\begin{array}{l}\text { Identificar as práticas, hábitos e bens de consumo que atuam como mediadores de } \\
\text { identificações por parte dos jovens que frequentam o Shopping de Ribeirão } \\
\text { Preto/SP. }\end{array}$ \\
\hline
\end{tabular}




\begin{tabular}{|l|l|}
\hline SOUZA, 2017 & Analisar a sociabilidade juvenil nos espaços dos Shopping Centers. \\
\hline TOMAZ, 2016 & $\begin{array}{l}\text { Analisar as relações entre consumo e juventude, identificando e estabelecendo, } \\
\text { com foco na formação de identidade, uma reflexão sobre este campo, a partir da } \\
\text { percepção de jovens das classes de baixa renda. }\end{array}$ \\
\hline
\end{tabular}
Fonte: Elaborado pelos autores (2021)

Verifica-se, num primeiro momento, que a maioria dos trabalhos tem uma preocupação maior em analisar os objetos de suas pesquisas, já que investigar, compreender e identificar são ações que aparecem uma só vez, mostrando que há, principalmente, um esforço em desdobrar e dar sentido aos fenômenos ligados ao consumo juvenil. De todos os objetivos gerais, cinco (BRANDÃO, BRASIL, TOMAZ, MORAES e PETENUSSI) se comprometem em analisar diretamente o consumo, enquanto os outros três sobrantes (COSTA, SOUZA e BARREIRO) possuem objetivos mais abrangentes, onde o consumo aparece ou de forma indireta e/ou inevitável. Também cabe ressaltar que chama a atenção o interesse de pesquisar em shoppings e mídias sociais, que possivelmente se dá por esses espaços serem pensados significativamente para o consumo.

Nesta parte podemos observar uma tabela que contém um levantamento dos autores selecionado nas referências bibliográficas de cada uma das oito obras captadas para este trabalho, bem como suas áreas de pesquisa. Cada autor (a) da lista ocupa um lugar específico por ter quatro vezes ou mais referenciadas, independente se a obra se repetia ou não. Abaixo também se pode ver que há duas categorias pelas quais os autores foram enquadrados: juventudes e consumo.

\section{Quadro 3 - lista dos principais autores}

\begin{tabular}{|l|l|c|}
\hline \multirow{5}{*}{ Juventudes } & ALMEIDA, Maria Isabel & Educação \\
\cline { 2 - 3 } & BARBOSA, Lívia & Antropologia \\
\cline { 2 - 3 } & BOURDIEU, Pierre & Sociologia \\
\cline { 2 - 3 } & DAYRELL, Juarez & Educação (vinculada a área da Sociologia) \\
\cline { 2 - 3 } & FEIXA, Carles & Antropologia \\
\cline { 2 - 3 } & NOVAES, Regina & Antropologia \\
\cline { 2 - 3 } Consumo & PAIS, José Machado & Sociologia \\
\hline & APPADURAI, Arjun & Antropologia \\
\cline { 2 - 3 } & BAUDRILLAR, Jean & Sociologia \\
\cline { 2 - 3 } & CAMPBELL, Colin & Antropologia \\
\cline { 2 - 3 } & CANCLINI, Nestor Garcia & Antropologia \\
\hline
\end{tabular}




\begin{tabular}{|l|l|c|}
\hline & DOUGLAS, Mary & Antropologia \\
\cline { 2 - 3 } & FEATHERSTONE, Mike & Sociologia \\
\cline { 2 - 3 } & ROCHA, Everardo & Antropologia \\
\hline
\end{tabular}

Fonte: Elaborado pelos autores (2021)

Analisando essa tabela observamos que, em relação a gênero, temos 4 mulheres em relação a 10 homens, o que retorna a uma desigualdade histórica em muitos campos da ciência. Os dois campos, o das juventudes e o do consumo, tiveram o mesmo número de autores; por outro lado, vemos a predominância das áreas das ciências sociais, o que demonstra que o tema juventudes e consumo está significativamente presente nessas áreas do conhecimento.

O presente quadro organiza as diferentes estratégias de coleta de dados utilizados pelos trabalhos de acordo com sua frequência, de maneira a objetivar essas informações.

Quadro 4 - estratégia de coleta de coleta de dados

\begin{tabular}{|c|c|}
\hline \multicolumn{2}{|c|}{ Principais estratégias de coleta de dados } \\
\hline Oficina de atividades & 1 \\
\hline Registros Imagéticos & 1 \\
\hline Conversas Informacionais & 1 \\
\hline Revisão Bibliográfia & 1 \\
\hline Entrevista & 5 \\
\hline Observação de Campo & 5 \\
\hline
\end{tabular}

Fonte: Elaborado pelos autores (2021)

Como podemos ver, então, a observação de campo é o método mais utilizado, seguida por entrevista. Tais métodos são comuns às ciências humanas, com destaque para as ciências sociais, o que mostra a forte presença destas áreas sobre o tema juventudes e consumo.

O quadro de conclusões abaixo foi criado a partir da seleção, por parte do pesquisador, de frases que chamaram a atenção nas conclusões/considerações finais e também pelos temas em comum que surgiram na leitura desta parte dos trabalhos. Cabe ressaltar que a tabela possui suas limitações, na medida em que determinados temas foram discutidos ao longo do trabalho, porém, não foram discutidos nas conclusões; sendo assim, pode ser errôneo dizer que tal tema não tenha sido discutido no trabalho. 
Quadro 5 - quadro de conclusões

\begin{tabular}{|l|c|c|c|c|c|c|c|c|}
\hline \multirow{2}{*}{$\begin{array}{l}\text { Principais temas } \\
\text { das conclusões }\end{array}$} & \multicolumn{9}{|c|}{ Autores selecionados } \\
\cline { 2 - 10 } & $\begin{array}{l}\text { Brandão, } \\
2015\end{array}$ & $\begin{array}{l}\text { Brasil, } \\
2015\end{array}$ & $\begin{array}{l}\text { Costa, } \\
2015\end{array}$ & $\begin{array}{l}\text { Tomaz, } \\
2016\end{array}$ & $\begin{array}{l}\text { Moraes, } \\
2017\end{array}$ & $\begin{array}{l}\text { Petenussi, } \\
2017\end{array}$ & $\begin{array}{l}\text { Souza, } \\
2017\end{array}$ & $\begin{array}{l}\text { Barreiro, } \\
2019\end{array}$ \\
\hline $\begin{array}{l}\text { Juventudes, } \\
\text { identidade e } \\
\text { consumo. }\end{array}$ & $\mathrm{X}$ & $\mathrm{X}$ & $\mathrm{X}$ & $\mathrm{X}$ & $\mathrm{X}$ & - & $\mathrm{X}$ & $\mathrm{X}$ \\
\hline $\begin{array}{l}\text { Juventudes, } \\
\text { cidadania e } \\
\text { consumo. }\end{array}$ & - & - & - & $\mathrm{X}$ & - & - & - & - \\
\hline $\begin{array}{l}\text { A relação entre } \\
\text { as mídias e } \\
\text { juventudes. }\end{array}$ & $\mathrm{X}$ & $\mathrm{X}$ & $\mathrm{X}$ & $\mathrm{X}$ & $\mathrm{X}$ & - & $\mathrm{X}$ & $\mathrm{X}$ \\
\hline $\begin{array}{l}\text { A relação entre } \\
\text { tecnologia e } \\
\text { juventudes. }\end{array}$ & - & $\mathrm{X}$ & - & - & - & $\mathrm{X}$ & $\mathrm{X}$ & $\mathrm{X}$ \\
\hline $\begin{array}{l}\text { Contribuição ao } \\
\text { campo da } \\
\text { Educação. }\end{array}$ & - & - & $\mathrm{X}$ & $\mathrm{X}$ & - & - & - & - \\
\hline $\begin{array}{l}\text { Pontos em } \\
\text { aberto para se } \\
\text { desenvolver em } \\
\text { futuras } \\
\text { pesquisas. }\end{array}$ & $\mathrm{X}$ & $\mathrm{X}$ & $\mathrm{X}$ & $\mathrm{X}$ & $\mathrm{X}$ & - & $\mathrm{X}$ & $\mathrm{X}$ \\
\hline
\end{tabular}

Fonte: Elaborado pelos autores (2021)

É difícil esse tipo de categorização dos trabalhos atuando somente sobre suas conclusões dado à riqueza de seus conteúdos, no entanto, é possível através dessa tabela perceber a abrangência dos trabalhos na síntese de todas as suas discussões, bem como a ausência destas, suas preocupações principais e o que mais for possível se abstrair a partir desses dados. Seguindo a análise, podemos observar logo de início que todos de alguma forma contribuíram para o debate sobre juventudes e consumo, o que mostra o alinhamento correto e a contribuição desses trabalhados selecionados para o tema desta pesquisa. Os dois primeiros assuntos mais abordados nas conclusões se referem à questão da identidade e consumo e à relação entre as mídias e juventudes. Consecutivamente temos a discussão sobre tecnologias e juventudes e cidadania e consumo. Quanto à contribuição à Educação, temos somente dois trabalhos com essa preocupação. Quase todos os trabalhos deixaram sugestões de pesquisa em aberto, o que permite investigações futuras sobre os temas.

\section{CONSIDERAÇÕES FINAIS}

Uma pesquisa que se propõe construir o estado de conhecimento tem como objetivo levantar as discussões mais recentes sobre um determinado assunto, limitado a um 
determinado espaço de tempo e que revelam as tendências de tal área de estudos. Para a construção do estado de conhecimento também é necessário traçar um panorama de tal ambiente de produção de conhecimento, que pode extravasar para escalas internacionais de análise.

No caso desta pesquisa, preocupou-se incialmente em traçar este panorama ainda no início dos resultados, através da parte com o subtítulo 'gráficos', com exceção da questão do gênero dos autores, que foi buscado na tabela anterior a esta parte. Pode-se observar uma divisão igualitária em termos de gênero nos trabalhos, pois, dos oito trabalhos capturados, quatro foram produzidos por pessoas do gênero feminino e os outros quatro do gênero masculino. Por outro lado, em relação às referências bibliográficas, observa-se uma maioria do gênero masculino, o que remonta uma desigualdade história nas ciências, onde o gênero masculino historicamente teve, e ainda tem maioria, com exceção de algumas outras áreas, como: pedagogia, enfermagem, nutrição, que estão de alguma forma relacionadas aos cuidados, e onde as mulheres são maioria, justamente pela noção preconceituosa que as condiciona nestes espaços - o que não quer dizer que elas nunca escolham estar genuinamente neles. Em seguida, pode se observar que destes oito, a maioria (cinco) dos trabalhos selecionados, estavam em nível de mestrado; enquanto que o restante (três), em nível de doutorado. Isso mostra que há a possiblidade de que aqueles que produziram em nível de mestrado possam ainda expandir o tema no doutorado - caso almejem tal formação.

Em relação ao recorte temporal desta pesquisa, verificou-se que os anos de maior produção foram os de 2015 a 2017, concentrando, em cada um dos anos, a publicação de três trabalhos; ou seja, dos cinco anos recortados, somente dois tiveram maior que um de trabalhos. No caso de 2018, onde houve um vácuo de produção, possivelmente aponta-se a falta de fomento e financiamento às ciências no Brasil, resultando numa tendência de baixa nas produções acadêmicas, ainda mais nas áreas da Educação e Ciências Humanas, as quais vêm recebendo muitos ataques e cortes orçamentais.

Em termos geográficos, somente em duas regiões das cinco no Brasil surgiram trabalhos: nordeste e sudeste, o que aponta um maior interesse dessas regiôes por tal tema. $\mathrm{O}$ ambiente de produção mostrou-se predominante dentro das instituições públicas, as quais detêm 6 trabalhos, enquanto que a PUC-RJ, a única instituição de ensino privada na lista, se destacou como a única com dois trabalhos sobre o tema. As bolsas de pesquisa, por sua vez, estiveram presentes na maioria dos trabalhos (cinco), sendo quase todas financiadas por instituições públicas, com destaque a CAPES, com exceção do PMCD, que se trata de um programa, porém, também recebe financiamento público. Tal panorama revela, 
principalmente, a importância do financiamento público na pesquisa, a começar pelo fato de que a maioria dos trabalhados selecionados foram financiados.

Traçado, então, o panorama do ambiente de produção de conhecimento no Brasil acerca do tema proposto, a próxima parte busca analisar o que se tem discutido acerca do tema juventudes e consumo. Juventudes e consumo por si só fazem parte de um amplo debate (OLIVEIRA; LACERDA, 2018; OLIVEIRA, 2019; 2020), que esteve e está na boca de grandes intelectuais, e isso pode ser verificado pela análise das referências utilizadas pelos autores dos trabalhos selecionados, que em sua maioria são cientistas sociais.

Tendo em vista o predomínio das Ciências Sociais sobre esse tema, que se demonstra pelas referências bibliográficas destacadas em cada um dos autores, justifica-se - pelo menos em parte - o porquê de os métodos mais utilizados nas pesquisas serem a entrevista, a observação de campo e a etnografia. Esses três métodos são clássicos nas Ciências Sociais, principalmente na brasileira, que se destaca pela pesquisa qualitativa.

Os trabalhos variam muito em relação ao modo como tratam o tema desta pesquisa, no entanto, pode-se traçar discussões comuns, que podem ser destacadas das considerações finais de cada trabalho. Sendo assim, chama a atenção como os temas identidade e mídias (tradicionais e digitais) são abordados pela maioria deles, o que de certa forma corrobora com as palavras chaves que circundam as mais frequentes - juventudes, consumo e jovens - na nuvem de palavras ilustrada nos resultados, tais como sociabilidade, identidade e comportamento, na medida em que se podem traçar relações diretas ou indiretas com estes temas. De certa forma, tais constatações mostram quais caminhos as pesquisas têm focado, e isso pode nortear futuras pesquisas para que aprofundem aquilo que foi pesquisado, mas que também explorem as lacunas que possam ser achadas, por exemplo, naquelas dimensões onde se pensa não ter explorado o suficiente do tema.

\section{REFERÊNCIAS}

BECKES, C. O que consome o adolescente? $1^{\circ}$ ed. Porto Alegre: Editora da UFRGS, 2016.

BRANDÃO, D. F. A. Consumo como experiência social: experimentações, vivências e práticas da cultura pop em um coletivo juvenil. Dissertação (Mestrado em Antropologia) Centro de Ciências Humanas, Letras e Artes, Universidade Federal da Paraíba. João Pessoa, 2015.

BARREIRO, R. G. Entre redes: juventudes, ambientes virtuais e vidas entretidas. Tese (Doutorado em Terapia Ocupacional) - Universidade Federal de São Carlos. São Carlos, 2019. 
BRASIL, W. S. O coletivo fora do eixo: juventude organizada, produção, circulação e consumo cultural. Dissertação (Mestrado em Sociologia) - Universidade Federal de Sergipe. São Cristóvão, 2015.

COSTA, G. M. M. As músicas veiculadas pelas mídias entre jovens: consumo, tendências e comportamentos. Tese (Doutorado em Educação) - Faculdade de Educação, Universidade Federal de Minas gerais. Belo Horizonte, 2015.

DAYREL, J. O jovem como sujeito social. Revista Brasileira de Educação, Rio de Janeiro, v. 5/6, n.24, p. 40-52, 2003. Disponível em: https://www.scielo.br/pdf/rbedu/n24/n24a04.pdf Acesso em: 05 jan 2021.

FERRAZ, A. P. C. M; BELHOT, R. V. Taxonomia de Bloom: revisão teórica e apresentação das adequações do instrumento para definição de objetivos instrucionais. Gest. Prod., São Carlos, $\quad$ v. 17, n. 2, p. 421-431,2010. Disponível em: http://www.scielo.br/scielo.php?script=sci_arttext\&pid=S0104530X2010000200015\&lng=pt \&nrm=iso Acesso em 05 jan 2021.

FONTANELLE, I. A. Cultura do consumo: fundamentos e formas contemporâneas. $1^{\circ}$ ed. Rio de Janeiro: Editora FGV, 2017.

GIL, A. C. Como elaborar projetos de pesquisa. 4. ed. São Paulo: Atlas, 2002.

MARX, K. O Capital: crítica da economia política. Tradução de Reginaldo Sant'Anna. 25. ed. Rio de Janeiro: Civilização Brasileira, 2008. Livro I, Volume 1 e 2.

MORAES, M. C. B. As It-girls e o "quê" a mais de luxo: cultura, juventude e mediação. Dissertação (Mestrado em Comunicação Social) - Pontifícia Universidade Católica do Rio de Janeiro. Rio de Janeiro, 2017.

MOROSINI, M. C; FERNANDES, C. M. B. Estado do Conhecimento: conceitos, finalidades e interlocuções. Educação Por Escrito, Porto Alegre, v.5, n.2, p.154- 164, jul./dez. 2014.

OLIVEIRA, V. H. N; LACERDA, M. P. C; SANTOS; A. M. Culturas juvenis e temas sensíveis ao contemporâneo - uma entrevista com Carles Feixa. Educar em Revista, v. 34, p. 311-325, 2018. Disponível em: https://revistas.ufpr.br/educar/article/view/58145/35929 Acesso em: 05 jan 2021.

OLIVEIRA, V. H. N; LACERDA, M. P. C. Culturas Juvenis e Pertencimento Urbano: Mapeando os Fluxos Juvenis na Cidade. Revista FSA, v. 15, n. 2, 2018. Disponível em: http://www4.unifsa.com.br/revista/index.php/fsa/article/view/1533 Acesso em: 05 jan 2021.

OLIVEIRA, V. H. N. (De) marcando a cidade: vivências urbanas de jovens-estudantes do Colégio de Aplicação da UFRGS. Cadernos do Aplicação (UFRGS), v. 31, p. 71-85, 2019. Disponível em: https://seer.ufrgs.br/CadernosdoAplicacao/article/view/82695 Acesso em: 05 jan 2021. 
OLIVEIRA, V. H. N. Pensando as juventudes, a escola e a cultura da paz. Cadernos da pedagogia (UFSCAR Online), v. 14, p. 256-258, 2020. Disponível em: http://www.cadernosdapedagogia.ufscar.br/index.php/cp/article/view/1393 Acesso em: 05 jan 2021.

OLIVEIRA, V. H. N. Juventudes e Educação: estado da arte de publicações em revistas A1 de universidades federais brasileiras (2010 - 2019). Educar Mais, v. 5, n. 2, 2021. Disponível em: http://periodicos.ifsul.edu.br/index.php/educarmais/article/view/2279 Acesso em: 25 jan 2021.

PAIS, J. M. A construção sociológica da juventude - alguns contributos. Análise Social, v. XXV, p. $139-165, \quad 1990 . \quad$ Disponível http://analisesocial.ics.ul.pt/documentos/1223033657F3sBS8rp1Yj72MI3.pdf Acesso em: 05 jan 2021.

PAIS, J. M; LACERDA, M. P. C; OLIVEIRA, V. H. N. Juventudes contemporâneas, cotidiano e inquietações de pesquisadores em Educação - uma entrevista com José Machado Pais. Educar em Revista, v. 64, p. 301-313, 2017. Disponível em: https://revistas.ufpr.br/educar/article/view/50119/32190 Acesso em: 05 jan 2021.

PETENUSSI, F. R. P. O mosaico das identificações juvenis via consumo: um estudo de antropologia urbana em um shopping de Ribeirão Preto/SP. Dissertação (Mestrado em Ciências Sociais) - Universidade Estadual Paulista "Júlio de Mesquita Filho". Araraquara, 2017.

SANTOS, G. B. B; OLIVEIRA, L. B; BARBOSA, J. S; OLIVEIRA, V. H. N. Culturas Juvenis: Um Estudo Sobre as Vivências dos Estudantes do Colégio de Aplicação da UFRGS. Revista FSA, v. 16, n. 2, 2019. Disponível em: http://www4.unifsa.com.br/revista/index.php/fsa/article/view/1729 Acesso em: 05 jan 2021.

SORIANO, R. R. Manual de pesquisa social. Tradução de Ricardo Rosenbusch. Petropolis, RJ: Vozes, 2004.

SOUZA, I. J. Andarilhos contemporâneos em Belém, a metrópole da Amazônia: consumo, juventudes e sociabilidade na era dos shoppings centers. Tese (Doutorado em Ciências Sociais) - Pontifícia Universidade Católica do Rio de Janeiro. Rio de Janeiro, 2017.

TOMAZ, C. J. Sociedade de consumo e juventude: uma análise a partir das práticas de consumo e identidade dos jovens vinculados ao Fundo de Financiamento Estudantil - FIES. Dissertação (Mestrado em Consumo, Cotidiano e Desenvolvimento Social) - Universidade Federal Rural de Pernanbuco. Recife, 2016. 


\section{Como Referenciar este Artigo, conforme ABNT:}

L. B. OLIVEIRA, V. H. N. OLIVEIRA, Estado do Conhecimento Sobre Juventudes e Consumo. Rev. FSA, Teresina, v.18, n. 03, art. 13, p. 279-298, mar. 2021.

\begin{tabular}{|l|c|c|}
\hline \multicolumn{1}{|c|}{ Contribuição dos Autores } & $\begin{array}{c}\text { L. B. } \\
\text { Oliveira }\end{array}$ & $\begin{array}{c}\text { V. H. N. } \\
\text { Oliveira }\end{array}$ \\
\hline 1) concepção e planejamento. & $\mathrm{X}$ & $\mathrm{X}$ \\
\hline 2) análise e interpretação dos dados. & $\mathrm{X}$ & $\mathrm{X}$ \\
\hline 3) elaboração do rascunho ou na revisão crítica do conteúdo. & $\mathrm{X}$ & $\mathrm{X}$ \\
\hline 4) participação na aprovação da versão final do manuscrito. & $\mathrm{X}$ & $\mathrm{X}$ \\
\hline
\end{tabular}

